\title{
Assessing the Anti-cancer Therapeutic Mechanism of a Herbal Combination for Breast Cancer on System-level by a Network Pharmacological Approach
}

\author{
HO-SUNG LEE and DAL-SEOK OH \\ The Herbal Medicine Research Division, Korea Institute of Oriental Medicine, Daejeon, Republic of Korea
}

\begin{abstract}
Background/Aim: Accumulating evidence has shown therapeutic effects of herbals on breast cancer, a commonly diagnosed malignancy in women worldwide. However, their underlying mechanisms remain unclear. We aimed to explore the mode of action of a recently developed herbal combination at system-level. Materials and Methods: We employed network pharmacological approaches to study the mechanism of a combination of three herbals, Astragalus membranaceus, Angelica gigas and Trichosanthes kirilowii by investigating active compounds and performing functional enrichment analysis for the interacting targets. Results: For in silico pharmacokinetic evaluation, ten active ingredients interacted with fifty-six breast cancer-associated therapeutic targets. Functional enrichment analysis revealed that TNF, estrogen, PI3K-Akt and MAPK signaling pathways were involved in tumorigenesis and development of breast cancer. The pharmacological mechanisms might be associated with cellular effects on proliferation, cell cycle process and apoptosis. Conclusion: The present study provides novel insights into the system-level pharmacological mechanisms underlying a herbal combination used for breast cancer therapies.
\end{abstract}

Breast cancer (BC) is the most commonly diagnosed female malignancy throughout women's life cycle (1). A growing body of evidence has demonstrated that $\mathrm{BC}$ is a multifactorial disease that is driven by a variety of genetic and epigenetic alterations and the subsequent dysregulation of diverse

This article is freely accessible online.

Correspondence to: Dal-Seok Oh, OMD, Ph.D., The Herbal Medicine Research Division, Korea Institute of Oriental Medicine 1672 Yuseong-daero, Yuseong-gu, Daejeon 34054, Republic of Korea. Tel: +82 428689494, Fax: +82 428629494, e-mail: dalsoh@gmail.com, dsoh@kiom.re.kr

Key Words: Systems biology, network pharmacology, herbal, combination, breast cancer, pharmacological mechanism. oncogenic signaling pathways (2). Recent advances in the elucidation of the molecular mechanisms underlying cancer progression have identified that the dysregulated pathways include estrogen, phosphatidylinositol 3-kinase (PI3K)-Akt, mitogen-activated protein kinase (MAPK), vascular endothelial growth factor receptor (vEGFR), Janus kinase (Jak)-signal transducer and activator of transcription (STAT), erythroblastic leukemia viral oncogene homologue (ErbB) and p53 signaling pathways (3-5). Current standard pharmacological care for BC therapies include conventional cytotoxic chemotherapy and molecular targeted therapy which aim to modulate the aberrant activation of these diverse oncogenic pathways (6). However, the use of cytotoxic chemotherapeutic agents has been reported to cause unwanted effects that adversely affect the quality of life (QoL) of cancer patients (7). Furthermore, the targeted anticancer drugs presently used in clinics are designed based on the 'one drug-one target' paradigm and therefore frequently have limited efficacy $(8,9)$. These issues underscore the importance of the development of anti-cancer therapies that can effectively target multiple oncogenic pathways with improved safety.

Meanwhile, herbals and their derived biochemical compounds are being recognized as effective therapeutic agents for cancer therapies $(10,11)$. Herbals, characterized by multiple compounds that affect multiple targets and pathways, have attracted much attention since they have been reported to possess potent anticancer properties through the modulation of multiple pathways relevant to the initiation and progression of cancer (12). An increasing number of clinical studies have also indicated their beneficial roles on improving QoL of cancer patients (7).

SH003 is the code name of a recently developed herbal combination that consists of three herbals, Astragalus membranaceus (Am), Angelica gigas (Ag) and Trichosanthes kirilowii (Tk) and has been shown to exert anticancer effects (13-21). It has been reported to efficiently suppress proliferation, growth, metastasis and angiogenesis. It has also been shown to induce apoptosis of various types of cancer cells including BC cells, in vitro and in vivo (22). Although 
the herbal combination has been shown to exhibit therapeutic activity in part by inhibiting key pro-tumorigenic pathways, such as STAT3/interleukin (IL)-6, VEGFR2 and extracellular signal-regulated kinase (ERK) signaling, its system-level pharmacological mechanism in $\mathrm{BC}$ has not been fully investigated yet.

Network pharmacology is an emerging interdisciplinary strategy that aims at the understanding of the underlying pharmacological mechanisms of herbal combinations from a systems perspective. This methodology has been widely applied to discover the major active compounds of herbals and their corresponding potential targets. It is also helpful in investigating the synergistic, additive, antagonistic or polypharmacological properties generated from the complicated interactions of multiple compounds and relevant targets at a complex network-level, which facilitates the elucidation of the modes of action of herbals $(12,23,24)$. In this study, we attempted to explore the therapeutic mechanism of the herbal combination SH003 for BC therapies at the systems-level using a network pharmacological approach.

\section{Materials and Methods}

Investigation on the chemical compounds. The chemical compounds of the three herbals Am, Ag and Tk, were obtained from traditional Chinese medicine (TCM) databases, such as, Traditional Chinese Medicine Systems Pharmacology (TCMSP) database, Herb Ingredients' Targets (HIT) database, Traditional Chinese Medicine Integrated Database (TCMID) and further manually supplemented through an extensive search of various articles (25-28). Note that in the case of Ag, we first retrieved the chemical components contained in Angelica gigas, a herbal of the Angelica genus widely used in China using the abovementioned TCM databases and integrated these results with the previously reported major compounds that are found in $\mathrm{Ag}$, including decursin, lomatin, and marmesin. Moreover, the chemical compounds that are not present in $\mathrm{Ag}$, such as, 4-octanone, isoeugenol and stigmasterol were omitted from the collected data based on previous experimental results (29-31).

Active compound screening. To identify the potential bioactive compounds of the SHOO3 herbal combination, we investigated the absorption, distribution, metabolism and excretion (ADME) profiles of each chemical compound derived from the three herbals, Am, Ag and Tk. In this study, the three most widely used pharmacokinetic parameters oral bioavailability (OB), Caco-2 permeability and druglikeness (DL) were evaluated using the TCMSP database (28). OB refers to the fraction of an orally administered dose that passes through the gastrointestinal epithelium towards the systemic circulation, and is detectable to targeted internal tissues and organs $(28,32)$. Caco-2 permeability is a widely applied index to predict the intestinal absorption of potential of drug molecules and chemical compounds, which is determined by measuring the rate of their diffusion mobility across the Caco-2 human large intestinal epithelial cancer cell line $(28,33,34)$. In general, chemical compounds whose Caco- 2 permeability is less than -0.4 are considered to be impermeable (35). DL is a qualitative index used to assess whether a prospective compound is chemically suitable for drug design based on its molecular properties and structural features (28). Chemical compounds without sufficient ADME information were excluded from the screening process and those with $\mathrm{OB} \geq$ $30 \%$, Caco- 2 permeability $\geq-0.4$ and $\mathrm{DL} \geq 0.18$ were considered to be pharmaceutically active compounds in each herbal, as suggested by previous studies $(28,36,37)$.

Investigation on target proteins interacting with the compounds. Human proteins that interact with the identified active compounds within the herbal combination were determined using the Search Tool for Interactions of Chemicals (STITCH) 5 database (38). The proteins interacting with the active compounds with confidence scores $\geq 0.7$ (a reference score for a high-confidence association as indicated by STITCH 5) under the 'Homo sapiens' species setting were considered as targets of the herbal combination. Human target genes and proteins of individual active compounds were also investigated using HIT and Therapeutic Target Database (TTD) databases (39). Information on target proteins including the name, protein ID and organism, was further confirmed using Uniprot (40). List of proteins associated with tumorigenesis and development of $\mathrm{BC}$ were obtained from various databases such as GeneCards (41), TTD (39), Online Mendelian Inheritance in Man (OMIM) (42), DrugBank (43), Pharmacogenomics Knowledge for Personalized Medicine (PharmGKB) (44), and DisGeNET (45) by using the search term, 'breast cancer' with search species limited to 'Homo sapiens'.

Network construction. The herb-compound (H-C) network was built by connecting the herbs with their active compounds, and the compound-target (C-T) network was constructed by linking the active compounds with their corresponding target proteins. The target-pathway (T-P) network was generated by the linkage of the target proteins and their related signaling pathways. All the networks were visualized by Cytoscape software (version 3.6.1) (46). In the networks, the nodes represent the herbs, active compounds, target proteins or signaling pathways and edges represent the interactions between the nodes.

Functional enrichment analysis. The functional enrichment analysis of distinct sets of target proteins was performed using g: Profiler, a web server-based tool used for the functional analysis of genes or proteins, and the Kyoto Encyclopedia of Genes and Genomes (KEGG) database $(47,48)$.

Calculation of contribution indices. To evaluate the contribution of individual active compounds to the anti-cancer effects of the herbal combination, a contribution index (CI) was calculated based on the network-based efficacy (NE) according to the following equations [1] and [2] as previously described $(37,49)$ :

$$
\begin{gathered}
N E(j)=\sum_{i=1}^{n} d_{i}[1] \\
C I(j)=\frac{c_{j} \times N E(j)}{\sum_{i=1}^{m} c_{i} \times N E(i)} \times 100 \%
\end{gathered}
$$

where $\mathrm{n}$ is the number of proteins targeted by compound $\mathrm{j}$; $d i$ is the degree of protein $i$ targeted by compound $j$; m is the number of compounds and $\mathrm{CI}$ is the number of studies relevant to both $\mathrm{BC}$ and compound $i$. To survey the literature correlated with $\mathrm{BC}$ and the active compounds, the term 'breast cancer' and the common names 


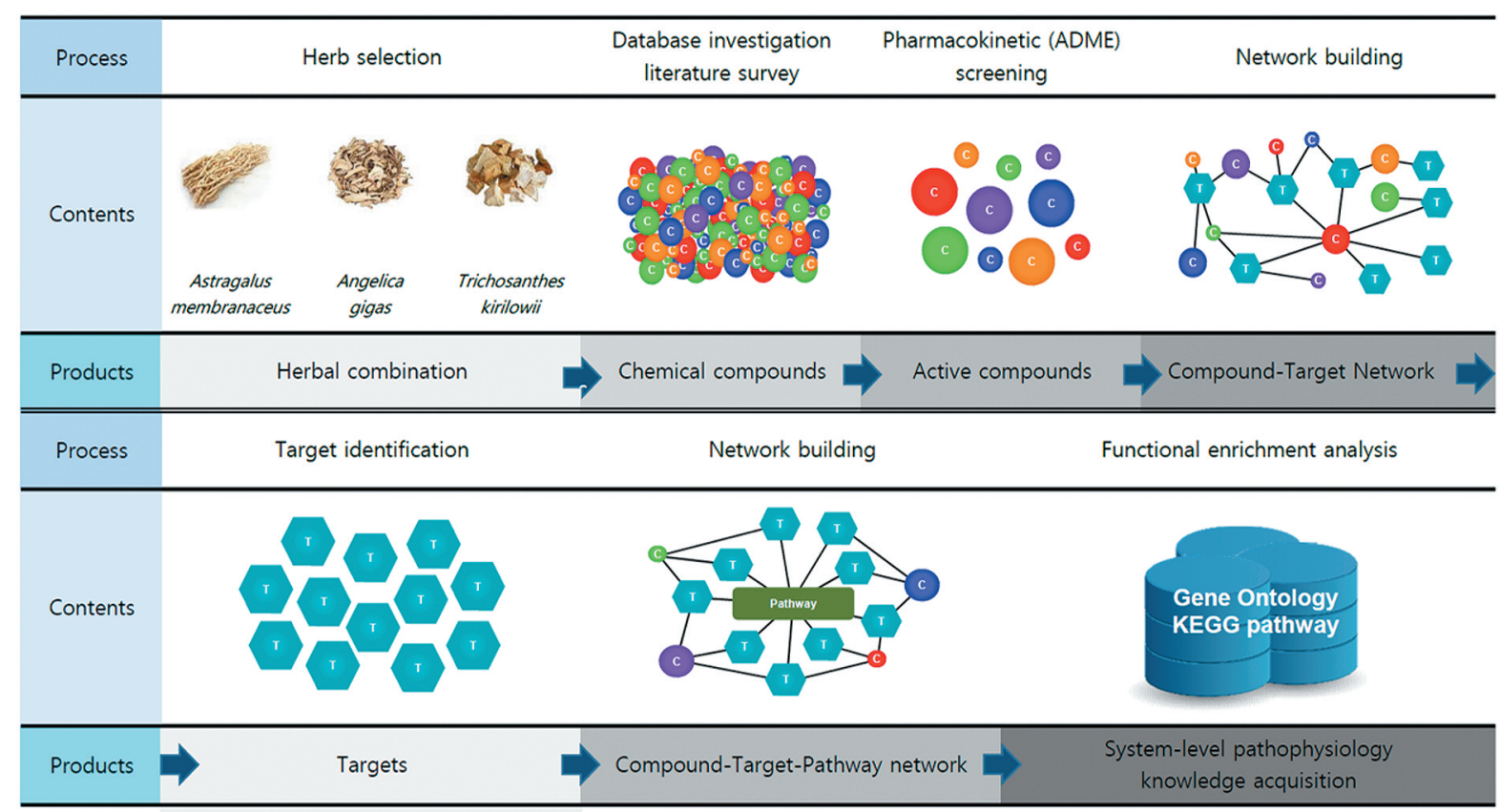

Figure 1. A schematic illustration representing the workflow for the network pharmacological analysis to reveal the therapeutic mechanisms of the herbal combination.

of compounds were used as search keywords. The number of articles published from 1990 to 2019 containing the aforementioned keywords in the abstract were obtained from PubMed. If the sum of the CIs for the top $\mathrm{N}$ compounds was greater than $85 \%$, these $\mathrm{N}$ compounds were considered the major contributors to the anti-cancer effects of the herbal combination as previously described $(37,49)$.

\section{Results}

The pharmacological mechanisms of the herbal combination against BC were explored at the systems-level. First, the chemical compounds of the herbals were collected from TCMrelated databases. Next, the pharmacokinetic parameters including OB, Caco-2 cell permeability, and DL, of individual compounds were evaluated to identify the potential bioactive compounds. Then, the human proteins targeted by the active compounds were determined via the investigation of the protein-chemical interaction data and functional enrichment analysis of the target proteins was performed. Afterwards, the comprehensive pharmacological information associated with the herbal combination was integrated into the $\mathrm{H}-\mathrm{C}, \mathrm{C}-\mathrm{T}$, and T-P networks and the underlying therapeutic mechanisms of the herbal medicine were analyzed (Figure 1).

Chemical compounds. The chemical compounds of the three herbals Am, Ag and Tk, were retrieved from a number of TCM databases (e.g., TCMSP, TCMID and HIT) and relevant literature $(25-27,37,49)$. As a result, 113, 154, and
80 compounds were retrieved for $\mathrm{Am}, \mathrm{Ag}$ and $\mathrm{Tk}$, respectively; 14 of those compounds were duplicates. Hence, a total of 331 compounds were identified after removing the duplicate phytochemicals.

Screening of the active phytochemical compounds. The in silico ADME system has been useful for the evaluation and screening of potent chemical compounds that may exhibit druggable pharmacokinetic activity $(28,37)$. As a result, 33 compounds were identified as active phytochemical compounds.

Investigation of the target proteins of the active compounds. We employed an in silico approach and analyzed the interactions between the herbal active compounds and proteins using the STITCH 5 database (38). As a result, we identified a total of 117 target proteins for the herbal combination (Figure 2).

Network-based investigation of the therapeutic profiles. To visualize the 'multi-compound, multi-target' bioactivity, we constructed herb-compound-target (H-C-T) network. Notably, in the network constructed in the present study, the nodes represent the herbals, active compounds, target proteins, or signaling pathways, and the edges represent the interactions between the nodes. The H-C-T network for the herbal combination consists of 130 nodes and 183 edges, including three herbals, 10 active compounds and 117 target proteins. 


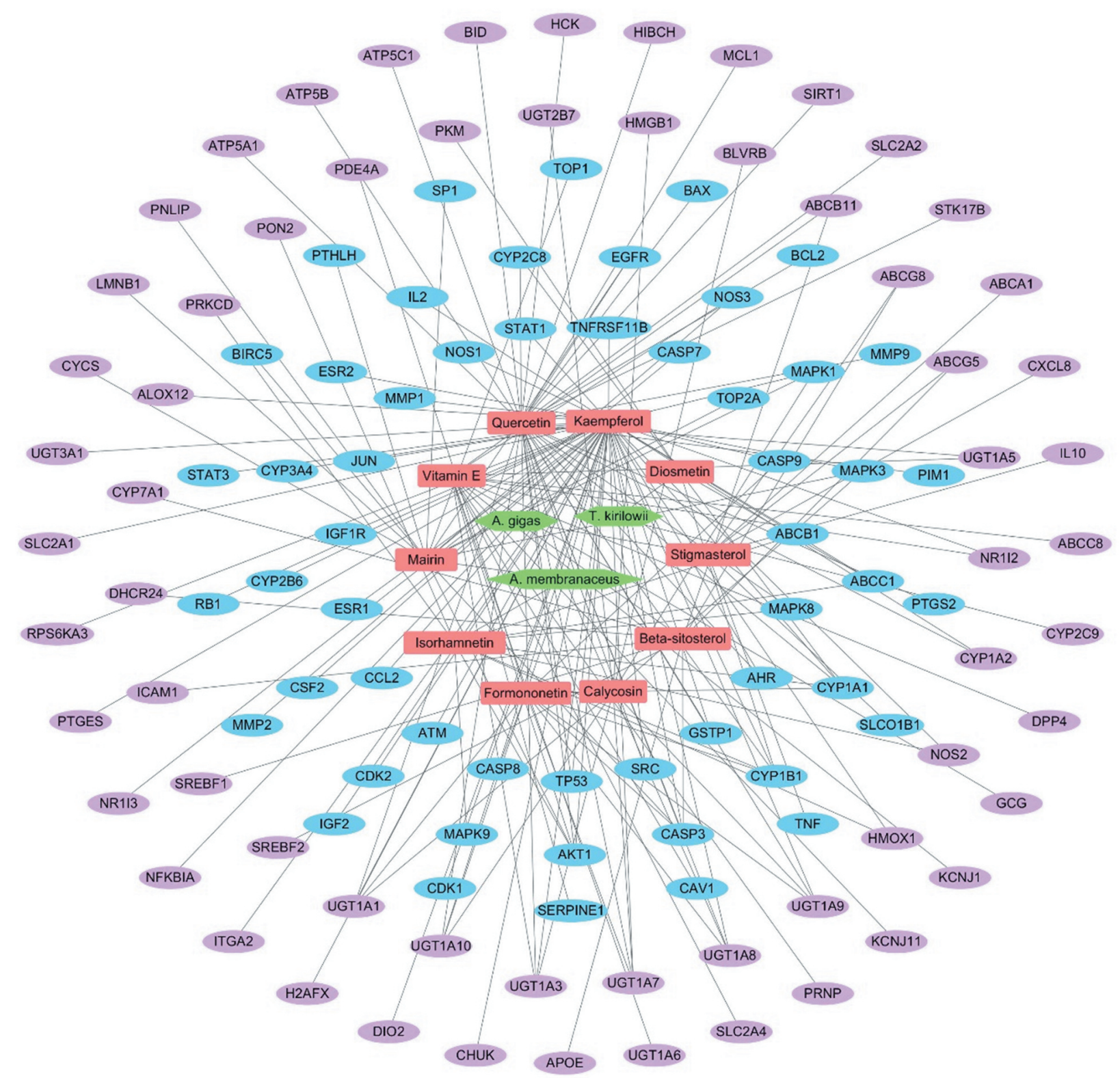

Figure 2. The herb-compound-target network. Green hexagons indicate the three herbal medicines comprising the herbal combination and red rectangles indicate their 10 active chemical compounds. Ovals represent the 117 targets of the active compounds of SH003, where those associated with breast cancer are colored in blue.

To further explore their systems-level pharmacological features based on a network perspective, a C-T network comprising 66 nodes and 89 edges was generated by linking the screened active compounds with their targets that are closely associated with BC (Figure 3). Note that the centralization and heterogeneity of the network were 0.411 and 2.163 , respectively. Among the $56 \mathrm{BC}$-associated targets of the herbal combination, AKT1 (degree=5), caspase-3
(CASP3; degree=5), CYP1A1 (degree=5) and CYP1B1 (degree $=5$ ) had the highest degree, indicating that they may act as important hub targets of the pharmacological activities of the herbal combination for BC therapy. These targets have been reported to be closely related to the pathogenesis and development of BC; AKT1 promotes the growth and tumorigenesis of $\mathrm{BC}$ cells in vitro and in vivo (50). The activity of caspase-3 may function as a potential determinant 


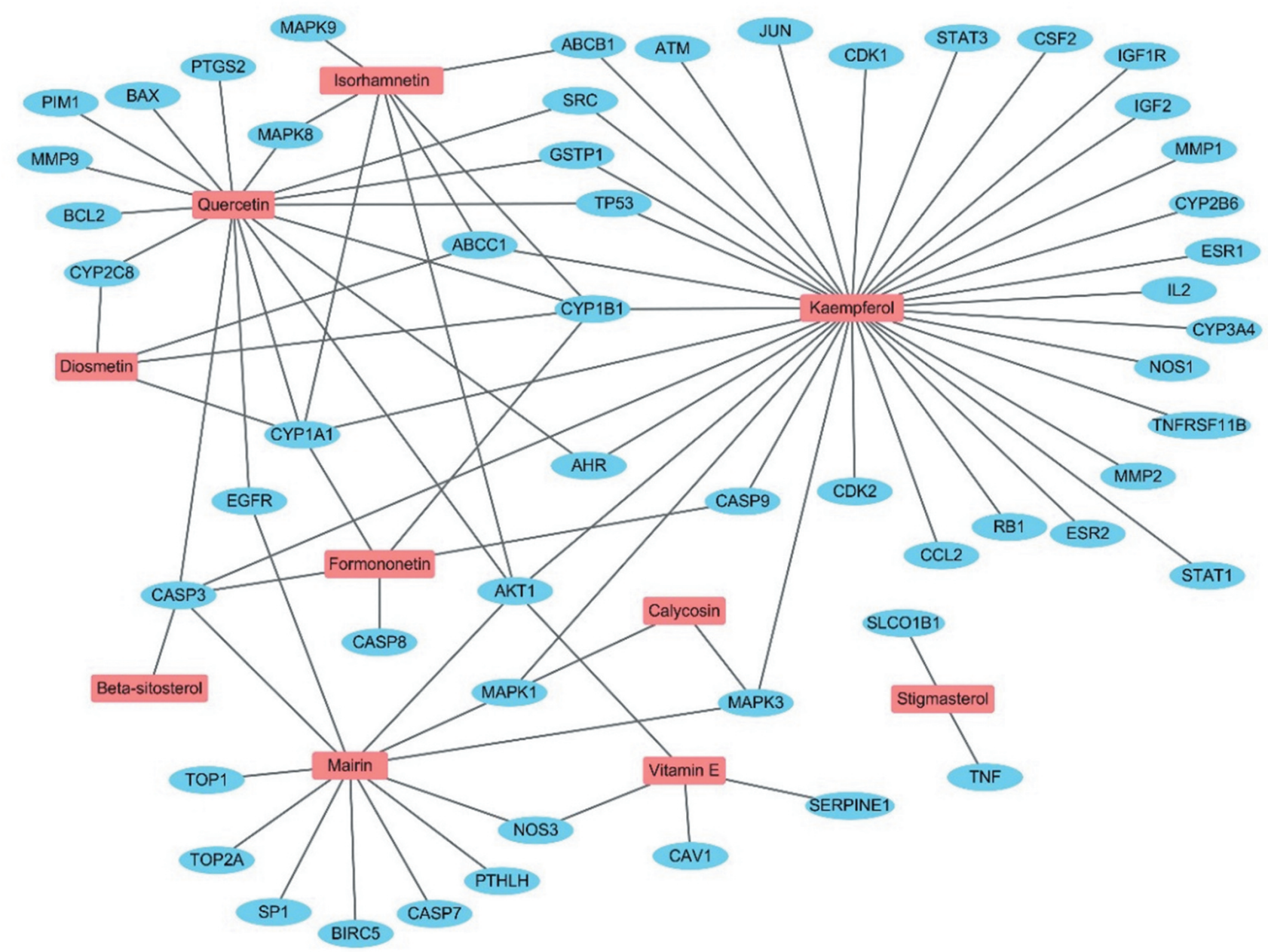

Figure 3. The compound-target network. Red rectangles indicate the 10 active chemical compounds in the herbal combination and blue ovals indicate their 56 breast cancer-associated targets.

of the survival or apoptosis of BC cells and tumors (51) and its expression levels have been associated with the survival rate of BC patients (52). CYP1A1 and CYP1A2, extrinsic pathways of the cytochrome P450 (CYP) superfamily, are key enzymes implicated in estrogen metabolism and may play important roles in the development, survival, proliferation and progression of $\mathrm{BC}(53,54)$.

To assess the contribution of individual active compounds to anticancer effects, the CI was calculated for every active compound based on NE as previously described (47). As a result, three compounds including quercetin, kaempferol and vitamin E were found to have high CIs with a sum of $89.42 \%$ (Figure 4).

Functional enrichment analysis of the herbal combinationassociated network. To investigate the biological characteristics

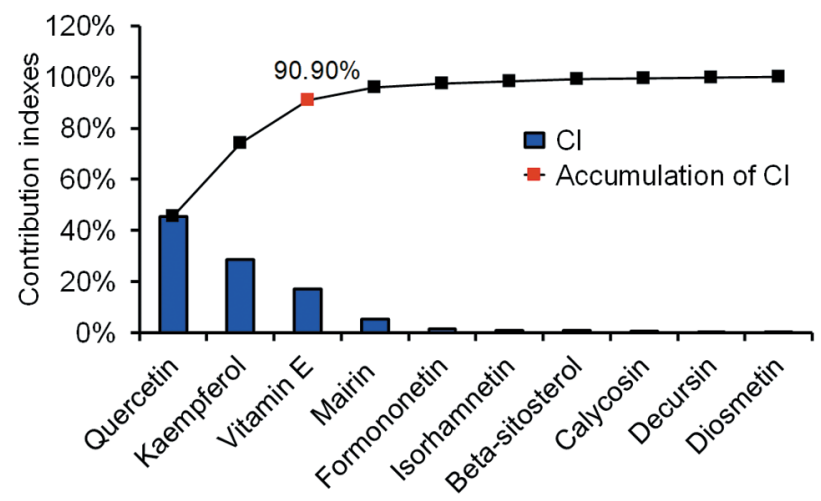

Figure 4. Analysis of the contribution index of individual active chemical compounds in the herbal combination. The sum of contribution indices for the top three active compounds, including quercetin, kaempferol, and vitamin E, was more than $85 \%$. 


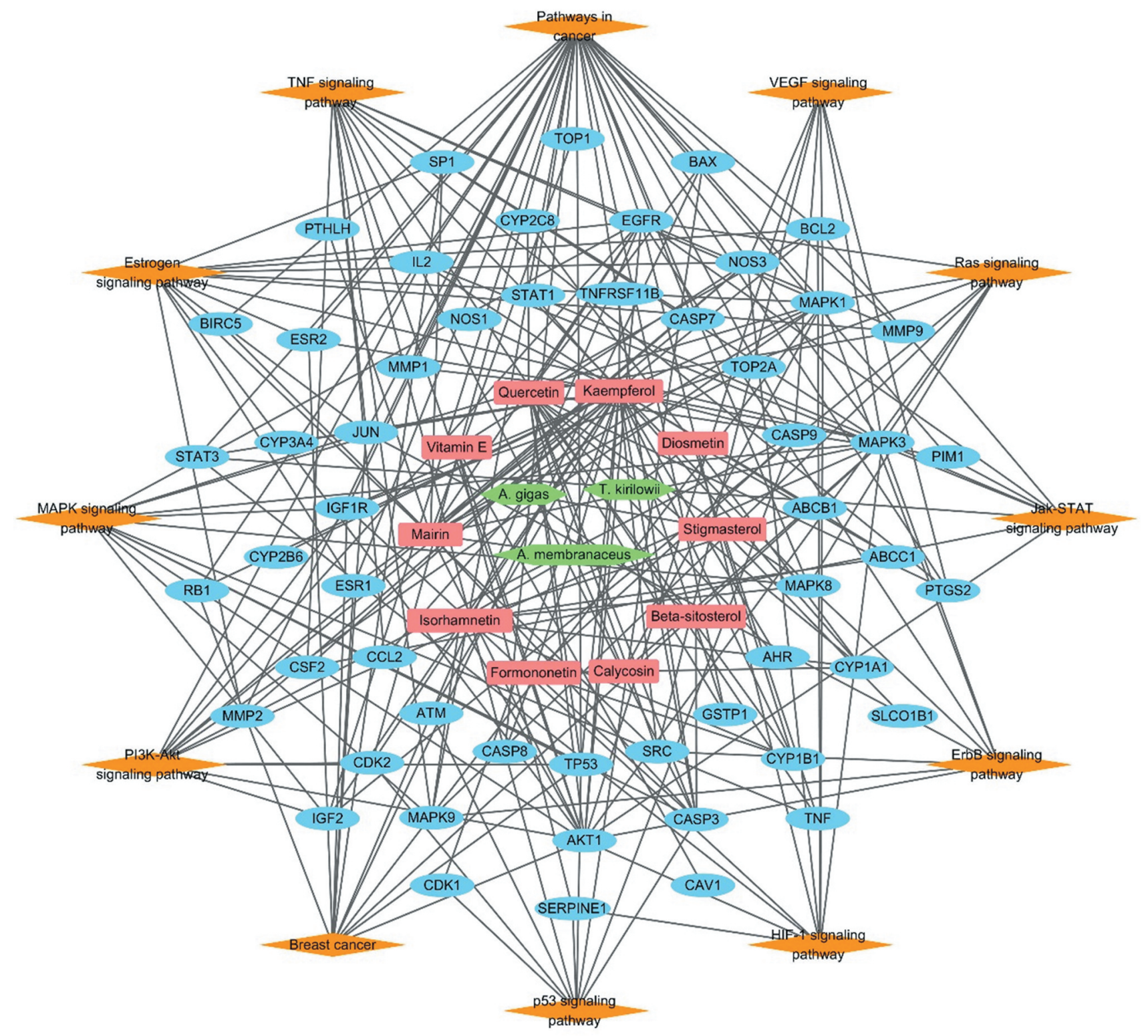

Figure 5. The Herb-Compound-Target-Pathway network. Green hexagons indicate the three herbals comprising the herbal combination and red rectangles indicate their 10 active chemical compounds. Blue ovals indicate the breast cancer-associated targets of the active compounds and orange diamonds indicate the signaling pathways enriched with the corresponding targets.

of the herbal combination-associated network, we performed gene ontology $(\mathrm{GO})$ enrichment analysis of the $\mathrm{BC}$-associated targets that interact with the active compounds of the herbal combination using g: Profiler (47). As a result, we found that the targets were significantly enriched for the genes/proteins associated with a variety of biological processes such as the positive regulation of cell death, apoptotic process or cell cycle arrest and negative regulation of cell proliferation and cell cycle process.
The aberrant regulation of diverse oncogenic signaling pathways is closely implicated in the tumorigenesis of various human cancers. To elucidate the underlying pharmacological mechanisms at the pathway level, we further conducted pathway enrichment analysis of its BCassociated targets based on the KEGG database. As a result, we found that the 'Pathways in Cancer' exhibited the highest number of target connections (degree=33), followed by the 'TNF signaling pathway', 'Estrogen signaling pathway', 
'Breast cancer' and 'PI3K-Akt signaling pathway' with 13 targets, and 'MAPK signaling pathway' with 12 targets (Figure 5).

Furthermore, the functional association of the BC-related targets of the herbal combination was analyzed using GeneMANIA, which facilitates the analysis and the prediction of functional interactions between multiple genes/proteins by integrating diverse types of biological information and data (55). The GeneMANIA analysis results demonstrated that among the BC-related targets of the three herbals, $32.33 \%$ were predicted to be co-expressed and $29.34 \%$ were predicted to have physical interactions.

\section{Discussion}

In this study, we attempted to identify the therapeutic mechanisms of action of a newly developed anticancer herbal combination for $\mathrm{BC}$, from a systems-perspective using network pharmacological approaches. Our novel findings obtained from this network analysis-based investigation led to the following conclusions. (i) Ten potential active compounds may interact with 56 BC-related targets to exert therapeutic actions. (ii) The targets interacting with the active compounds are enriched for genes/proteins associated with a variety of biological processes, including positive regulation of cell death, apoptotic process, or cell cycle arrest and negative regulation of cell proliferation or cell cycle process. (iii) The targets are further enriched in multiple pathways in tumorigenesis and development of BC.

The network pharmacological analysis identified 10 active compounds that may interact with 56 BC-related targets. These active compounds, including isorhamnetin (56), kaempferol (57), diosmetin (58), quercetin (59), mairin (betulinic acid) (60), decursin (61), formononetin (62), $\beta$ sitosterol (63) and calycosin (64) have been reported to exhibit antitumor activities in BC. Isorhamnetin is known to inhibit cell proliferation and induce apoptosis in human BC via the regulation of MAPK and PI3K/Akt pathways (56). Moreover, kaempferol, diosmetin, mairin and quercetin have been shown to function by inducing cell cycle arrest of human BC cells $(57,58,65,66)$. Decursin inhibits Pin1 activation and promotes its association with p53 (67). Together, these findings reveal the chemical basis of the pharmacological effects of the herbal combination on BC therapy. Note that among the active compounds, quercetin, kaempferol and vitamin $\mathrm{E}$ may be the major contributors to the pharmacological effects of the herbal combination based on the CIs analysis.

Previous studies have reported that the herbal combination suppresses the growth and metastasis of human BC cells by inhibiting the activity of the STAT3/IL-6 axis (17). They can also modulate the activities of key oncogenic signaling pathways in vitro and in vivo, including ERK, VEGF and $\mathrm{PI} 3 \mathrm{~K} / \mathrm{mTOR}$ pathways, which may lead to the induction of cell cycle arrest, apoptosis and antiangiogenic processes in various types of cancer cells (22). These experimental observations are consistent with the network pharmacologybased analysis results (Figure 4). Further experimental studies are warranted to validate the pharmacological mechanisms of the herbals.

In summary, by employing network pharmacological approaches, we explored the underlying pharmacological mechanisms of the SH003 herbal combination from a systems-perspective. We found that the targets interacting with the active compounds were functionally enriched in multiple pathways that are closely associated with tumorigenesis and development of $\mathrm{BC}$, including the TNF signaling pathway, estrogen signaling pathway, PI3K-Akt signaling pathway and MAPK signaling pathway.

\section{Conflicts of Interest}

The Authors declare that the research was conducted in the absence of any commercial or financial relationships that could be construed as a potential conflict of interest.

\section{Authors' Contributions}

Conceptualization, HSL and DSO; methodology, HSL and DSO; software, HSL; validation, HSL and DSO; formal analysis, HSL; data curation, HSL and DSO; writing the first draft, HSL; drafting, DSO; supervising, DSO; funding acquisition, DSO.

\section{Acknowledgements}

The study was funded by Korea Institute of Oriental Medicine (KIOM, grant \#KSN2013310).

\section{References}

1 DeSantis CE, Fedewa SA, Goding Sauer A, Kramer JL, Smith RA and Jemal A: Breast cancer statistics, 2015: Convergence of incidence rates between black and white women. CA Cancer J Clin 66: 31-42, 2016. PMID: 26513636. DOI: 10.3322/caac.21320

2 Eroles P, Bosch A, Perez-Fidalgo JA and Lluch A: Molecular biology in breast cancer: intrinsic subtypes and signaling pathways. Cancer Treat Rev 38: 698-707, 2012. PMID: 22178455. DOI: $10.1016 / j . c t r v .2011 .11 .005$

3 Synnott NC, Bauer MR, Madden S, Murray A, Klinger R, O'Donovan N, O'Connor D, Gallagher WM, Crown J, Fersht AR and Duffy MJ: Mutant p53 as a therapeutic target for the treatment of triple-negative breast cancer: Preclinical investigation with the anti-p53 drug, PK11007. Cancer Lett 414: 99-106, 2018. PMID: 29069577. DOI: 10.1016/j.canlet.2017.09.053

4 Hosford SR and Miller TW: Clinical potential of novel therapeutic targets in breast cancer: CDK4/6, Src, JAK/STAT, PARP, HDAC, and PI3K/AKT/mTOR pathways. Pharmagenomics Pers Med 7: 203-215, 2014. PMID: 25206307. DOI: 10.2147/PGPM.S52762 
5 Sarid D, Ron IG, Shoshan L, Barnea I, Shina S, Baratz M, Greenberg J, Merimsky O, Ben-Yosef R, Lev-Ari S, Keidar Y and Yaal-Hahoshen N: Invasive breast cancer treated with taxol and epirubicin neo-adjuvant chemotherapy: The role in the outcome of the "crosstalk" between Erb receptors and p53. Anticancer Res 28: 3147-3152, 2008. PMID: 19031973.

6 Florea AM and Busselberg D: Cisplatin as an anti-tumor drug: cellular mechanisms of activity, drug resistance and induced side effects. Cancers (Basel) 3: 1351-1371, 2011. PMID: 24212665. DOI: $10.3390 /$ cancers3011351

7 Miller KD, Siegel RL, Lin CC, Mariotto AB, Kramer JL, Rowland JH, Stein KD, Alteri R and Jemal A: Cancer treatment and survivorship statistics, 2016. CA Cancer J Clin 66: 271-289, 2016. PMID: 27253694. DOI: $10.3322 /$ caac. 21349

8 Zimmermann GR, Lehar J and Keith CT: Multi-target therapeutics: when the whole is greater than the sum of the parts. Drug Discov Today 12: 34-42, 2007. PMID: 17198971. DOI: 10.1016/j.drudis.2006.11.008

9 Imming P, Sinning C and Meyer A: Drugs, their targets and the nature and number of drug targets. Nat Rev Drug Discov 5: 821834, 2006. PMID: 17016423. DOI: $10.1038 /$ nrd2132

10 Ohnishi S and Takeda H: Herbal medicines for the treatment of cancer chemotherapy-induced side effects. Front Pharmacol 6: 14, 2015. PMID: 25713534. DOI: 10.3389/fphar. 2015.00014

11 Harvey AL, Edrada-Ebel R and Quinn RJ: The re-emergence of natural products for drug discovery in the genomics era. Nat Rev Drug Discov 14: 111-129, 2015. PMID: 25614221. DOI: $10.1038 / \mathrm{nrd} 4510$

12 Poornima P, Kumar JD, Zhao Q, Blunder M and Efferth T: Network pharmacology of cancer: From understanding of complex interactomes to the design of multi-target specific therapeutics from nature. Pharmacol Res 111: 290-302, 2016. PMID: 27329331. DOI: 10.1016/j.phrs.2016.06.018

13 Seo HS, Ku JM, Lee HJ, Woo JK, Cheon C, Kim M, Jang BH, Shin YC and Ko SG: SH003 reverses drug resistance by blocking signal transducer and activator of transcription 3 (STAT3) signaling in breast cancer cells. Biosci Rep 37, 2017. PMID: 28864784. DOI: 10.1042/BSR20170125

14 Choi HS, Cho SG, Kim MK, Lee HJ, Moon SH, Jang HJ and Ko SG: SH003 enhances paclitaxel chemosensitivity in MCF7/PAX breast cancer cells through inhibition of MDR1 activity. Mol Cell Biochem 426: 1-8, 2017. PMID: 27854072. DOI: 10.1007/s11010-016-2875-y

15 Woo SM, Kim AJ, Choi YK, Shin YC, Cho SG and Ko SG: Synergistic effect of SH003 and doxorubicin in triple-negative breast cancer. Phytother Res 30: 1817-1823, 2016. PMID: 27476488. DOI: $10.1002 /$ ptr.5687

16 Choi EK, Kim SM, Hong SW, Moon JH, Shin JS, Kim JH, Hwang IY, Jung SA, Lee DH, Lee EY, Lee S, Kim H, Kim D, Kim YS, Choi YK, Kim HI, Choi HS, Cho SG, Kim JE, Kim KP, Hong YS, Lee WK, Lee JS, Kim TW, Ko SG and Jin DH: SH003 selectively induces p73 dependent apoptosis in triplenegative breast cancer cells. Mol Med Rep 14, 3955-3960, 2016. PMID: 27599791. DOI: 10.3892/mmr.2016.5722

17 Choi YK, Cho SG, Woo SM, Yun YJ, Park S, Shin YC and Ko SG: Herbal extract SH003 suppresses tumor growth and metastasis of MDA-MB-231 breast cancer cells by inhibiting STAT3-IL-6 signaling. Mediators Inflamm 2014: 492173, 2014. PMID: 24976685. DOI: 10.1155/2014/492173
18 Kongtun S, Jiratchariyakul W, Kummalue T, Tan-ariya P, Kunnachak S and Frahm AW: Cytotoxic properties of root extract and fruit juice of Trichosanthes cucumerina. Planta Med 75: 839842, 2009. PMID: 19288406. DOI: 10.1055/s-0029-1185455

19 Shin JW, Son JY, Kang JK, Han SH, Cho CK and Son CG: Trichosanthes kirilowii tuber extract induces G2/M phase arrest via inhibition of tubulin polymerization in HepG2 cells. J Ethnopharmacol 115: 209-216, 2008. PMID: 18022775. DOI: 10.1016/j.jep.2007.09.030.

20 Zang W, Bian H, Huang X, Yin G, Zhang C, Han LI, Hao P, Ding S, Sun YU, Yang Z, Hoffman RM and Tang D: Traditional Chinese Medicine (TCM) Astragalus Membranaceus and Curcuma Wenyujin promote vascular normalization in tumorderived endothelial cells of human hepatocellular carcinoma. Anticancer Res 39: 2739-2747, 2019. PMID: 31177109. DOI: 10.21873/anticanres. 13400

21 Cheng XD, Hou CH, Zhang XJ, Xie HY, Zhou WY, Yang L, Zhang SB and Qian RL: Effects of Huangqi (Hex) on inducing cell differentiation and cell death in K562 and HEL cells. Acta Biochim Biophys Sin (Shanghai) 36: 211-217, 2004. PMID: 15202506. DOI: $10.1093 / \mathrm{abbs} / 36.3 .211$

22 Lee KM, Lee K, Choi YK, Choi YJ, Seo HS and Ko SG: SH003 induced G1 phase cell cycle arrest induces apoptosis in HeLa cervical cancer cells. Mol Med Rep 16: 8237-8244, 2017. PMID: 28944910. DOI: 10.3892/mmr.2017.7597

23 Zhou X, Seto SW, Chang D, Kiat H, Razmovski-Naumovski V, Chan K and Bensoussan A: Synergistic effects of Chinese Herbal Medicine: A comprehensive review of methodology and current research. Front Pharmacol 7: 201, 2016. PMID: 27462269. DOI: 10.3389/fphar.2016.00201

24 Huang C, Zheng C, Li Y, Wang Y, Lu, A and Yang L: Systems pharmacology in drug discovery and therapeutic insight for herbal medicines. Brief Bioinform 15: 710-733, 2014. PMID: 23736100. DOI: 10.1093/bib/bbt035

25 Huang L, Xie D, Yu Y, Liu H, Shi Y, Shi T and Wen C: TCMID 2.0: a comprehensive resource for TCM. Nucleic Acids Res 46: D1117-D1120, 2018. PMID: 29106634. DOI: 10.1093/nar/gkx 1028

26 Xue R, Fang Z, Zhang M, Yi Z, Wen C and Shi T: TCMID: Traditional Chinese Medicine integrative database for herb molecular mechanism analysis. Nucleic Acids Res 41: D1089D1095, 2013. PMID: 23203875. DOI: $10.1093 / \mathrm{nar} / \mathrm{gks} 1100$

27 Ye H, Ye L, Kang H, Zhang D, Tao L, Tang K, Liu X, Zhu R, Liu Q, Chen YZ, Li Y and Cao Z: HIT: linking herbal active ingredients to targets. Nucleic Acids Res 39: D1055-1059, 2011. PMID: 21097881. DOI: 10.1093/nar/gkq1165.

28 Ru J, Li P, Wang J, Zhou W, Li B, Huang C, Li P, Guo Z, Tao W, Yang Y, Xu X, Li Y, Wang Y and Yang L: TCMSP: a database of systems pharmacology for drug discovery from herbal medicines. J Cheminform 6: 13, 2014. PMID: 24735618. DOI: $10.1186 / 1758-2946-6-13$

29 Ok S, Oh SR, Jung TS, Jeon SO, Jung JW and Ryu DS: Effects of Angelica gigas Nakai as an anti-inflammatory agent in in vitro and in vivo atopic dermatitis models. Evid Based Complement Alternat Med 2018: 2450712, 2018. PMID: 29713361. DOI: $10.1155 / 2018 / 2450712$

30 Jeong SY, Kim HM, Lee KH, Kim KY, Huang DS, Kim JH and Seong RS: Quantitative analysis of marker compounds in Angelica gigas, Angelica sinensis, and Angelica acutiloba by HPLC/DAD. Chem Pharm Bull (Tokyo) 63, 504-511, 2015. PMID: 25946978. DOI: 10.1248/cpb.c15-00081 
31 Kim MR, Abd El-Aty AM, Kim IS and Shim JH: Determination of volatile flavor components in danggui cultivars by solvent free injection and hydrodistillation followed by gas chromatographicmass spectrometric analysis. J Chromatogr A 1116: 259-264, 2006. PMID: 16620859. DOI: 10.1016/j.chroma.2006.03.060

32 Wang CK and Craik DJ: Cyclic peptide oral bioavailability: Lessons from the past. Biopolymers 106: 901-909, 2016. PMID: 27178381. DOI: $10.1002 /$ bip. 22878

33 Kono Y, Iwasaki A, Matsuoka K and Fujita T: Effect of mechanical agitation on cationic liposome transport across an unstirred water layer in Caco-2 cells. Biol Pharm Bull 39: 12931299, 2016. PMID: 27476939. DOI: 10.1248/bpb.b16-00050

34 Volpe DA: Variability in Caco-2 and MDCK cell-based intestinal permeability assays. J Pharm Sci 97: 712-725, 2008. PMID: 17542022. DOI: $10.1002 / j p s .21010$

35 Zhang J, Li Y, Chen X, Pan Y, Zhang S and Wang Y: Systems pharmacology dissection of multi-scale mechanisms of action for herbal medicines in stroke treatment and prevention. PLoS One 9: e102506, 2014. PMID: 25093322. DOI: 10.1371/ journal.pone.0102506

36 Huang J, Cheung F, Tan HY, Hong M, Wang N, Yang J, Feng Y and Zheng Q: Identification of the active compounds and significant pathways of yinchenhao decoction based on network pharmacology. Mol Med Rep 16: 4583-4592, 2017. PMID: 28791364. DOI: $10.3892 / \mathrm{mmr} .2017 .7149$

37 Yue SJ, Xin LT, Fan YC, Li SJ, Tang YP, Duan JA, Guan HS and Wang CY: Herb pair Danggui-Honghua: mechanisms underlying blood stasis syndrome by system pharmacology approach. Sci Rep 7: 40318, 2017. PMID: 28074863. DOI: $10.1038 /$ srep40318

38 Szklarczyk D, Santos A, von Mering C, Jensen LJ, Bork P and Kuhn M: STITCH 5: augmenting protein-chemical interaction networks with tissue and affinity data. Nucleic Acids Res 44: D380-D384, 2016. PMID: 26590256. DOI: 10.1093/nar/gkv1277

39 Zhu F, Han B, Kumar P, Liu X, Ma X, Wei X, Huang L, Guo Y, Han L, Zheng C and Chen Y: Update of TTD: Therapeutic target database. Nucleic Acids Res 38: D787-D791, 2010. PMID: 19933260. DOI: $10.1093 / \mathrm{nar} / \mathrm{gkp} 1014$

40 The UniProt Consortium. UniProt: the universal protein knowledgebase. Nucleic Acids Res 46: 2699, 2018. PMID: 27899622. DOI: $10.1093 / \mathrm{nar} / \mathrm{gky} 092$

41 Safran M, Dalah I, Alexander J, Rosen N, Iny Stein T, Shmoish M, Nativ N, Bahir I, Doniger T, Krug H, Sirota-Madi A, Olender T, Golan Y, Stelzer G, Harel A and Lancet D: GeneCards Version 3: the human gene integrator. Database (Oxford) 2010: baq020, 2010. PMID: 20689021. DOI: 10.1093/database/baq020

42 Amberger JS, Bocchini CA, Schiettecatte F, Scott AF and Hamosh A: OMIM.org: Online Mendelian Inheritance in Man (OMIM $®)$, an online catalog of human genes and genetic disorders. Nucleic Acids Res 43: D789-798, 2015. PMID: 25428349. DOI: 10.1093/nar/gku1205

43 Wishart DS, Feunang YD, Guo AC, Lo EJ, Marcu A, Grant JR, Sajed T, Johnson D, Li C, Sayeeda Z, Assempour N, Iynkkaran I, Liu Y, Maciejewski A, Gale N, Wilson A, Chin L, Cummings R, Le D, Pon A, Knox C and Wilson M: DrugBank 5.0: a major update to the DrugBank database for 2018. Nucleic Acids Res 46: D1074-D1082, 2018. PMID: 29126136. DOI: 10.1093/nar/gkx1037

44 Whirl-Carrillo M, McDonagh EM, Hebert JM, Gong L, Sangkuhl K, Thorn CF, Altman RB and Klein TE: Pharmacogenomics knowledge for personalized medicine. Clin Pharmacol Ther 92: 414-417, 2012. PMID: 22992668. DOI: 10.1038/clpt.2012.96

45 Piñero J, Bravo À, Queralt-Rosinach N, Gutiérrez-Sacristán A, Deu-Pons J, Centeno E, García-García J, Sanz F and Furlong LI: DisGeNET: a comprehensive platform integrating information on human disease-associated genes and variants. Nucleic Acids Res 45: D833-D839, 2017. PMID: 27924018. DOI: 10.1093/nar/gkw943

46 Shannon P, Markiel A, Ozier O, Baliga NS, Wang JT, Ramage D, Amin N, Schwikowski B and Ideker T: Cytoscape: a software environment for integrated models of biomolecular interaction networks. Genome Res 13: 2498-2504, 2003. PMID: 14597658. DOI: $10.1101 /$ gr.1239303

47 Reimand J, Arak T, Adler P, Kolberg L, Reisberg S, Peterson H and Vilo J: g:Profiler-a web server for functional interpretation of gene lists (2016 update). Nucleic Acids Res 44: W83-89, 2016. PMID: 27098042. DOI: 10.1093/nar/gkw199

48 Kanehisa M and Goto S: KEGG: kyoto encyclopedia of genes and genomes. Nucleic Acids Res 28: 27-30, 2000. PMID: 10592173. DOI: $10.1093 / \mathrm{nar} / 28.1 .27$

49 Yue SJ, Liu J, Feng WW, Zhang FL, Chen JX, Xin LT, Peng C, Guan HS, Wang CY and Yan D: System pharmacology-based dissection of the synergistic mechanism of Huangqi and Huanglian for diabetes mellitus. Front Pharmacol 8: 694, 2017. PMID: 29051733. DOI: 10.3389/fphar.2017.00694

50 Riggio M, Perrone MC, Polo ML, Rodriguez MJ, May M, Abba M, Lanari C and Novaro V: AKT1 and AKT2 isoforms play distinct roles during breast cancer progression through the regulation of specific downstream proteins. Sci Rep 7: 44244, 2017. PMID: 28287129. DOI: 10.1038/srep44244

51 Yang XH, Sladek TL, Liu X, Butler BR, Froelich CJ and Thor AD: Reconstitution of caspase 3 sensitizes MCF-7 breast cancer cells to doxorubicin- and etoposide-induced apoptosis. Cancer Res 61: 348-354, 2001. PMID: 11196185.

$52 \mathrm{Pu}$ X, Storr SJ, Zhang Y, Rakha EA, Green AR, Ellis IO and Martin SG: Caspase-3 and caspase- 8 expression in breast cancer: caspase-3 is associated with survival. Apoptosis 22: 357-368, 2017. PMID: 27798717. DOI: 10.1007/s10495-016-1323-5

53 Rodriguez M and Potter DA: CYP1A1 regulates breast cancer proliferation and survival. Mol Cancer Res 11: 780-792, 2013. PMID: 23576571. DOI: 10.1158/1541-7786.MCR-12-0675

54 Huang Y, Trentham-Dietz A, Garcia-Closas M, Newcomb PA, Titus-Ernstoff L, Hampton JM, Chanock SJ, Haines JL and Egan KM: Association of CYP1B1 haplotypes and breast cancer risk in Caucasian women. Cancer Epidemiol Biomarkers Prev 18: 1321-1323, 2009. PMID: 19293312. DOI: 10.1158/10559965.EPI-08-0853.

55 Montojo J, Zuberi K, Rodriguez H, Bader GD and Morris Q: GeneMANIA: Fast gene network construction and function prediction for Cytoscape. F1000Res 3: 153, 2014. PMID: 25254104. DOI: 10.12688/f1000research.4572.1

$56 \mathrm{Hu} \mathrm{S}$, Huang L, Meng L, Sun H, Zhang W and Xu Y: Isorhamnetin inhibits cell proliferation and induces apoptosis in breast cancer via Akt and mitogenactivated protein kinase kinase signaling pathways. Mol Med Rep 12: 6745-6751, 2015. PMID: 26502751. DOI: $10.3892 / \mathrm{mmr} .2015 .4269$

57 Zhu L and Xue L: Kaempferol suppresses proliferation and induces cell cycle arrest, apoptosis, and DNA damage in breast cancer cells. Oncol Res 27: 629-634, 2018. PMID: 2973949. DOI: $10.3727 / 096504018 X 15228018559434$ 
58 Androutsopoulos VP, Mahale S, Arroo RR and Potter G: Anticancer effects of the flavonoid diosmetin on cell cycle progression and proliferation of MDA-MB 468 breast cancer cells due to CYP1 activation. Oncol Rep 21, 1525-1528, 2009. PMID: 19424633. DOI: 10.3892/or_00000384

59 Choi JA, Kim JY, Lee JY, Kang CM, Kwon HJ, Yoo YD, Kim TW, Lee YS and Lee SJ: Induction of cell cycle arrest and apoptosis in human breast cancer cells by quercetin. Int J Oncol 19: 837-844, 2001. PMID: 11562764. DOI: 10.3892/ijo.19.4.837

60 Luo R, Fang D, Chu P, Wu H, Zhang Z and Tang Z: Multiple molecular targets in breast cancer therapy by betulinic acid. Biomed Pharmacother 84: 1321-1330, 2016. PMID: 27810789. DOI: $10.1016 /$ j.biopha.2016.10.018

61 Jiang C, Guo J, Wang Z, Xiao B, Lee HJ, Lee EO, Kim SH and $\mathrm{Lu} \mathrm{J}$ : Decursin and decursinol angelate inhibit estrogenstimulated and estrogen-independent growth and survival of breast cancer cells. Breast Cancer Res 9: R77, 2007. PMID: 17986353. DOI: $10.1186 /$ bcr1790

62 Chen J, Zeng J, Xin M, Huang W and Chen X: Formononetin induces cell cycle arrest of human breast cancer cells via IGF1/PI3K/Akt pathways in vitro and in vivo. Horm Metab Res 43: 681-686, 2011. PMID: 21932171. DOI: 10.1055/s-00311286306.

63 Awad AB, Roy R and Fink CS: Beta-sitosterol, a plant sterol, induces apoptosis and activates key caspases in MDA-MB-231 human breast cancer cells. Oncol Rep 10: 497-500, 2003. PMID: 12579296.
64 Chen J, Hou R, Zhang X, Ye Y, Wang Y and Tian J: Calycosin suppresses breast cancer cell growth via ERbeta-dependent regulation of IGF-1R, p38 MAPK and PI3K/Akt pathways. PLoS One 9: e91245, 2014. PMID: 24618835. DOI: 10.1371/journal.pone.0091245

65 Mertens-Talcott SU, Noratto GD, Li X, Angel-Morales G and Bertoldi MC: Safe, S. Betulinic acid decreases ER-negative breast cancer cell growth in vitro and in vivo: role of $\mathrm{Sp}$ transcription factors and microRNA-27a:ZBTB10. Mol Carcinog 52: 591-602, 2013. PMID: 22407812. DOI: 10.1002/mc.21893

66 Choi EJ and Ahn WS: Kaempferol induced the apoptosis via cell cycle arrest in human breast cancer MDA-MB-453 cells. Nutr Res Pract 2: 322-325, 2008. PMID: 20016737. DOI: 10.4162/ nrp.2008.2.4.322

$67 \mathrm{Kim}$ JH, Jung JH, Kim SH and Jeong SJ: Decursin exerts anticancer activity in MDA-MB-231 breast cancer cells via inhibition of the Pin 1 activity and enhancement of the Pin1/p53 association. Phytother Res 28: 238-244, 2014. PMID: 23580332. DOI: $10.1002 /$ ptr.4986

Received May 29, 2020

Revised June 22, 2020

Accepted June 23, 2020 